\title{
IMPORTÂNCIA EPIDEMIOLÓGICA DE ALGUNS ANIMAIS SILVESTRES NA ESQUISTOSSOMOSE MANSÔNICA *
}

\author{
Urara Kawazoe ** \\ Antonio Carlos Mattos Pinto***
}

KAWAZOE, U. \& PINTO, A. C. M. Importância epidemiológica de alguns animais silvestres na esquistossomose mansônica. Rev. Saúde públ., S. Paulo, 17:345-66, 1983.

RESUMO: Com o intuito de averiguar a importância de alguns roedores como possíveis reservatórios do S. mansoni, na ausência do homem parasitado, foi realizada pesquisa, visando contribuir para o esclarecimento de aspectos ligados à cadeia epidemiológica da esquistossomose, bem como conhecer alguns parâmetros da biologia de certos roedores, em seu habitat semi-natural. O experimento foi realizado num viveiro de $952 \mathrm{~m}^{2}$, no município de Taubaté, São Paulo (Brasil), numa área endêmica de esquistossomose mansônica humana, e teve a duração de três anos e seis meses (agosto de 1973 a dezembro de 1976). Foram utilizados como hospedeiros definitivos, Holochilus brasiliensis leucogaster, Zygodontomys lasiurus, Oryzomys nigripes eliurus e Cavia aperea aperea; como hospeideiro intermediário, Biomphalaria tenagophila e posteriormente B. glabrata. Entre agosto de 1973 e janeiro de 1976, não houve encontro de $B$. tenagophila eliminando cercárias de S. mansoni; não se verificou, também, infecção natural de roedores. Em agosto de 1975, houve introdução acidental de desovas da $\mathbf{B}$. glabrata, cujos adultos, em 1976, apresentaram infecção por S. mansoni em três ocasiōes, com indices de 2,$0 ; 1,6$ e $0,8 \%$. No mesmo ano de 1976, dois Holochilus, nascidos no Viveiro, eliminaram ovos viáveis de $\mathbf{S}$. mansoni. Foi possivel obter dados de 41 H. b. leucogaster, 28 introduzidos e 14 nascidos no local. O exemplar que sobreviveu mais tempo completou 346 dias. Os animais nascidos no viveiro e capturados pela primeira vez pesavam, em média, 20 a $50 \mathrm{~g}$. Notou-se que o peso corporal aumentou com o tempo $\theta$ parece não estacionar até a morte do animal. $\mathbf{Z}$. lasiurus e $\mathbf{C}$. a aperea não procriaram e nem adquiriram infecção ao $\mathbf{S}$. mansoni. 0 . n. eliurus, procriou e permaneceu vivo, em média, menos de 100 dias; não foi observada eliminação de ovos do parasita. E pouco provável que $\mathbf{H}$. b. leucogaster e B. tenagophila mantenham o ciclo da esquistossomose na ausência da contaminação humana, na natureza. Porém, é possível que, futuramente, $\mathbf{H}$. b. leucogaster na presença de B. glabrata, possa servir de reservatório da esquistossomose, na natureza, quando encontrados em abundância e desde que adaptados com cepas adequadas do parasita.

UNITERMOS: Esquistossomose mansônica. Schistosoma mansoni. Biomphalaria glabrata. Biomphalaria tenagophila. Holochilus brasiliensis leucogaster. Reservatório.

* Parte da Tese de Doutorado apresentada ao Departamento de Parasitologia do Instituto de Ciências Biomédicas da Universidade de São Paulo, 1980, subordinada ao título. "Sobre o comportamento de alguns animais silvestres na epidemiologia da esquistossomose mansônica humana". Financiado pela Fundação de Amparo à pesquisa do Estado de São Paulo (Processo no 72.284).

** Do Departamento de Parasitologia do Instituto de Biologia da Universidade de Campinas (UNICAMP) - Caixa Postal 6.109 - 13.100 - Campinas, SP - Brasil.

*** Da Superintendencia de Controle de Endemias(SUCEN) da Secretaria da Saúde do Estado de São Paulo - 12.100 - Taubaté, SP - Brasil. 
KAWAZOE, U. \& PINTO, A.C.M. Importancia epidemiologica de alguns animais silvestres na esquỉstossomose mansônica. Rev. Saúde puibl., S. Paulo, 17:345-66, 1983.

\section{INTRODUÇAO}

O primeiro encontro de animais naturalmente parasitados pelo Schistosoma mansoni, no Brasil, foi relatado por Amorim ${ }^{1}$ (1953), que alertou para o possivel papel de mamíferos, como reservatório desta parasitose e a provável manutenção do ciclo paralelo desta helmintose, juntamente como 0 homem.

Os relatos de roedores mais freqüentemente capturados com infecção natural de S. mansonit, em áreas endêmicas de alta e média intensidades de esquistossomose humana, têm sido verificados com as espécies Holochilus brasiliensis, Nectomys squamipes e com menor freqüência em Oxymycterus sp.. As duas primeiras espécies apresentam hábìtos semi-aquáticos e frequentam regularmente as coleçōes hidricas próximas do seu habitat natural. Outros roedores com menor índice de infecção natural também têm sido encontrados naturalmente infectados com $S$. mansoni como é o caso de Cavia aperea, Zygodontomys lasiurus e Oryzomys nigripes.

Holochilus brasiliensis $(=$ Holochilus sciureus), espécie que será estudada mais especificamente neste trabalho, tem sido encontrado com índices de infecção natural de $31,1 \%$ em Alagoas (Amorim 1,2,3, 1953, 1962; Amorim e col. $\left.{ }^{4}, 1954\right)$; 20,0\% em Sergipe (Piva e Barros $\left.{ }^{32}, 1966\right) ; 17,9 \%$ em Pernambuco (Barbosa e col.9, 1971 e Barbosa 7, 1972); 39,3\% em Minas Gerais (Carvalho ${ }^{13}, 1974$ ) e $42,2 \%$ em São Paulo (Bastos 12, 1975; Dias 18, 1976; Dias 19, 1978 e Kawazoe e col..22, 1978).

Essa espécie, encontrada com relativa frequiência na natureza, tem sido responsável pelo grande número de casos positivos de $S$. mansoni, com número elevado de vermes adultos nos órgãos internos, bem como a eliminação de ovos viáveis através das fezes.

Os indices de infecção natural em roedores, apresentados nos diversos trabalhos publicados, não refletem a situação da população como um todo, mas somente dos exemplares capturados. Além disso, devido a diferença de local e época de captura, a comparação desses resultados torna-se difícil. No entanto, quase todos os autores que discutem a possível importância desses roedores, na manutenção do ciclo de $S$. mansoni, na natureza, deixam em aberto a questão da sua real participação em determinadas áreas pelo fato de nāo terem conseguido provar a existência de ciclos isolados, na ausência do homem (Martins e col. ${ }^{26}$, 1955; Martins ${ }^{25}$, 1958; Barbosa e col. ${ }^{8}$, 1953; Barretto ${ }^{11}, 1964$; Amorim $^{3}$, 1962; Barretto ${ }^{10}$, 1959; Piva e Barros ${ }^{32}$, 1966 e Antunes 5, 1971). Esses mencionados autores têm sentido a necessidade de estudos especificos com o intuito de verificar o real papel daqueles roedores na epidemiologia da esquistossomose mansônica, definindo sua posição na cadeia epidemiológica da helmintose. Até o momento, as opiniōes têm sido controvertidas: alguns autores atribuem aos roedores uma participação ativa na transmissão da doença; outros consideram que os mesmos seriam hospedeiros acidentais e não conseguiriam manter o ciclo do parasita, em zonas de focos esporádicos ou em regióes onde nāo houvesse a esquistossomose humana.

Em trabalhos recentes realizados no Brasil, Antunes ${ }^{5}$ (1971) e Carvalho ${ }^{13}$ (1974) conseguiram completar o ciclo do $S$. mansoni em roedores, na ausência do homem, em Belo Horizonte ( $M G$ ), träbalhanc'o em locais por eles considerados "semi-naturais". Antunes ${ }^{5}$ (1971) utilizou como local um serpentário de formato semi-circular medindo $11,05 \mathrm{~m}$ de diâmetro e $9,2 \mathrm{~m}$ em seu maior comprimento. Esse serpentário era circundado por um fosso cheio d'água, de $0,90 \mathrm{~m}$ de largura por $0,70 \mathrm{~m}$ de profundidade. Utilizou o modelo Nectomys squamipes - Biomphalaria glabrata - Nectomys squamipes. Carvalho 13 (1974) utilizou o modelo $B$. glabrata - Holochilus 
KAWAZOE, U. \& PINTO, A.C.M. Importância epidem.ológıca de alguns animais silvestres na esquisiossomose mansônica. Rev. Saúde públ., S. Paulo, 17:345-66, 1983.

brasiliensis - B. glabrata, em um viveiro "semi-natural", de formato retangular $(3,5 \times 4,0 \mathrm{~m})$, cercado de tela de arame e coberto com telhas. No seu interior foi construído um bebedouro semi-circular, com capacidade para 60 litros d'água onde foram colocados os planorbideos infectados. Apesar do sucesso dos experimentos, os autores deixam em aberto a questão do papel dos roedores na epidemiologia da esquistossomose mansônica, pois seriam necessários outros estudos complementares relacionados principalmente com a biologia e a ecologia de tais animais, até então sem nenhum estudo mais pormenorizado em nosso país.

Em 1976, Dias ${ }^{18}$, tentou elucidar alguns dos itens em aberto, principalmente relacionados com a ecologia de alguns roedores, numa área endêmica da esquistossomose humana, no município de Taubaté. Utilizou o sistema de captura, marcação, libertação e recaptura dos roedores encontrados na fauna local. O autor observou entre outros fatores: tempo de permanência, domínio vital, distância percorrida, densidade populacional, ciclos sazonais e época de reprodução dos roedores, referindo-se mais precisamente à espécie Holochilus brasiliensis leucogaster, roedor com alto indice de positividade natural ao $\boldsymbol{S}$. mansoni, naquela região. Em relação ao papel desse roedor na epidemiologia da esquistossomose, baseado em observaçōes de exame parasitológico de fezes, oograma, encontro de vermes adultos nos animais naturalmente parasitados, relacionados com alguns fatores ecológicos, Dias sugere a importância do Holochilus, embora na dependência da sua densidade populacional que, na área estudada, era baixa.

Apesar do trabalho acima estar relacionado com a ecologia de roedores suscetiveis ao $S$. mansoni e com a epidemiologia da esquistossomose, ainda resta a dúvida quanto a importância desses roedores como disseminadores de ovos desta verminose na ausência do homem parasitado.
$O$ presente trabalho teve como objetivo tentar esclarecer os aspectos ligados à cadeıa epıdemılógica da esquistossomose, bem como observar a biologia de alguns roedores, em seu habitat sem1-natural.

\section{MATERIAL E ME'IODOS}

Este trabalho foi realizado durante o período de agosto de 1973 a dezembro de 19.6 numa área de média endemicidade de esquistossomose mansônica humaná, denominada Bairro do Barranco, a $7 \mathrm{~km}$ do centro da cidade de Taubaté. Este município está localizado no Vale do Rio Paraíba do Sul (23 $01^{\prime}$ de latitude sul e $45^{\circ} 33^{\prime}$ de longitude), no Estado de São Paulo. Nessa regıão encontra-se um dos focos importantes de esquistossomose humana do Estado, tendo sido registrados índices de prevalência de $9,6 \%, 7,3 \%$ e $4,1 \%$ nos anos de 1974,1975 e 1976, respectivamente.

No locaal citado, foi isolada uma área de $\$ 52 \mathrm{~m}^{2}$ utilizando-se placas pré-fabricadas de cimento, apoiadas lateralmente em postes de cimento, também pré-fabricados. A 50 $\mathrm{cm}$ acima do solo foi colocada uma aba contínua de metal galvanizado com $15 \mathrm{~cm}$ de largura, acompanhando horizontalmente toda a parede do local, para impedir a entrada e a saida de animais. Este local, denominado Viveiro, ficou constituído por um trapézio de superfície bastante plana, apresentando declive para o lado de maior comprimento. Ao longo da parede contigua ao lado mais baixo, foi escavada uma valeta de $50 \mathrm{~m}$ de comprimento, $50 \mathrm{~cm}$ de largura e $50 \mathrm{~cm}$ de profundidade, forrada com argila, a fim de impedir a infiltração da água. Esta vala foi abastecida com água, encanada em tubos plásticos, proveniente de nascente d'água e protegida com caixa de cimento. A água excedente da vala do Viveiro era escoada, através de manilhas, para um esgoto situado a cerca de $40 \mathrm{~m}$. Foi colocada uma tela metálica na entrada da primeira manilha de tubulação do escoa- 
KAWAZOE, U. \& PINTO, A.C.M. Importância epidemiológica de alguns animais silvestres na esquistossomose mansônica. Rev. Saúde públ., S. Paulo, 17:345-66, 1983.

mento, para evitar a evasão de pianorbídeos e outros animais.

A vegetação do Viveiro era constituida essencialmente por espécies ruderais, dois bambusais e alguns pés de cana-de-açúcar. No início de 1976 , foi feito plantio de milho, ao longo da valá, a fim de aproveitar as espigas, como complemento alimentar dos roedores. A representação esquemática e a vista fotográfica da área encontram-se nas figuras 1 e 2 .

\section{Procedimento no Viveiro}

Para as observações do ciclo evolutivo do $S$. mansoni foram utilizados como hospedeiro vertebrado, os seguintes animais silvestres: Holochilus brasiliensis leucogaster (Brandt, 1827) - rato-de-cana; $Z$ ygodontomys lasiurus (Wagner, 1845) - rato-de-campo; Oryzomys nigripes eliurus (Wagner, 1845) -rato-de-arroz; todas da familia Cricetidae; e Cavia aperea aperea Erxleben, 1777 preá, pertencente a família Caviidae. Foram também realizadas observações biolúgicas desses roedores utilizando-se os seguintes parâmetors: época de reprodução, peso e medida do corpo, número de animais nascidos no Viveiro e a longevidade dos mesmos nesse ambiente.

Esses animais foram colocados aleatoriamente dentro do Viveiro, após ter sido certificada a ausência de qualquer animal, para que não houvesse um número excessivo de roedores no local, de modo que cada exemplar tivesse condições de espaço e alimentação, bem como possibilidade para reprodução. Para evitar escassez alimentar, houve complementação com ração utilizada no biotério, depositada em locais protegidos perto das armadilhas.

Os roedores colocados no Viveiro foram capturados em fazendas da visinhança e mantidos em cativeiro até ter-se certeza da sua negatividade à infecção pelo $S$. mansoni, ou foram utilizados filhotes nascidos no laboratório. Inicialmente, foram colo- cados 2 exemplares machos de Holochilus previamente infectados com aproximadamente 100 cercárias e niais 4 exemplares machos e 5 fêmeas não infectados.

Para a captura dos roedores foram utilizadas armadilhas tipo "mlaleta" ou "gaicla", de arame trefilado, com porta basculante, sem mola, medindo $15 \times 15 \times 30 \mathrm{~cm}$ e $17 \times 17 \times 40$ $\mathrm{cm}$. Utilizou-se milho, banana, mandioca e maçã como isca, tendo sido usadas com maior freqüência as duas primeiras. Foram empregadas 16 armadilhas, entre agosto de 1973 a julho de 1974 e 19 , entre agosto de 1974 a dezembro de 1976. As capturas foram feitas semanaimente, tendo sido as armadilhas, providas com isca, instaladas às $17 \mathrm{~h}$ de um dia e recolhidas às $7,30 \mathrm{~h}$ do dia seguinte, devido ao hábito noturno dos roedores. As armadilhas foram sempre colocadas em locais pré-determinados de tal modo que cobrisse igualmente toda extensão do Viveiro.

Planorbídeos da espécie Biomphalaria tenagophila foram utilizados como hospedeiro intermediário por ser a única espécie transmissora da esquistossomose mansônica na região. Exemplares adultos e desovas criados no laboratório ou capturados em criadouros naturais existentes no municipio de Taubaté foram colocados na vala existente dentro do Viveiro, após veriticada a completa ausência dos planorbídeos. As coletas de caramujos foram realizadas sistematicamente, cada 15 dias, utilizando-se o tempo de $30 \mathrm{~min}$ para a captura de maior número possivel de exemplares, percorrendo-se toda extensão da vala. Em agosto de 1975 , constatada a inexistência de planorbídeos na vala, foram colocadas no local desovas provenientes do laboratório, supostamente da espécie $B$. tenagophila. Após o crescimento dos caramujos, verificou-se ter havido um equivoco, pois os mesmos eram da espécie $B$. glabrata.

A limpeza da vala era executada quando julgada necessária, conforme o crescimento da vegetação ao seu redor. 
KAWAZOE, U. \& PINTO, A.C.M. Importancia epidemiológica de alguns animais silvestres na esquistossomose mansônica. Rev. Saûde públ., S. Paulo, 17:345-66, 1983.

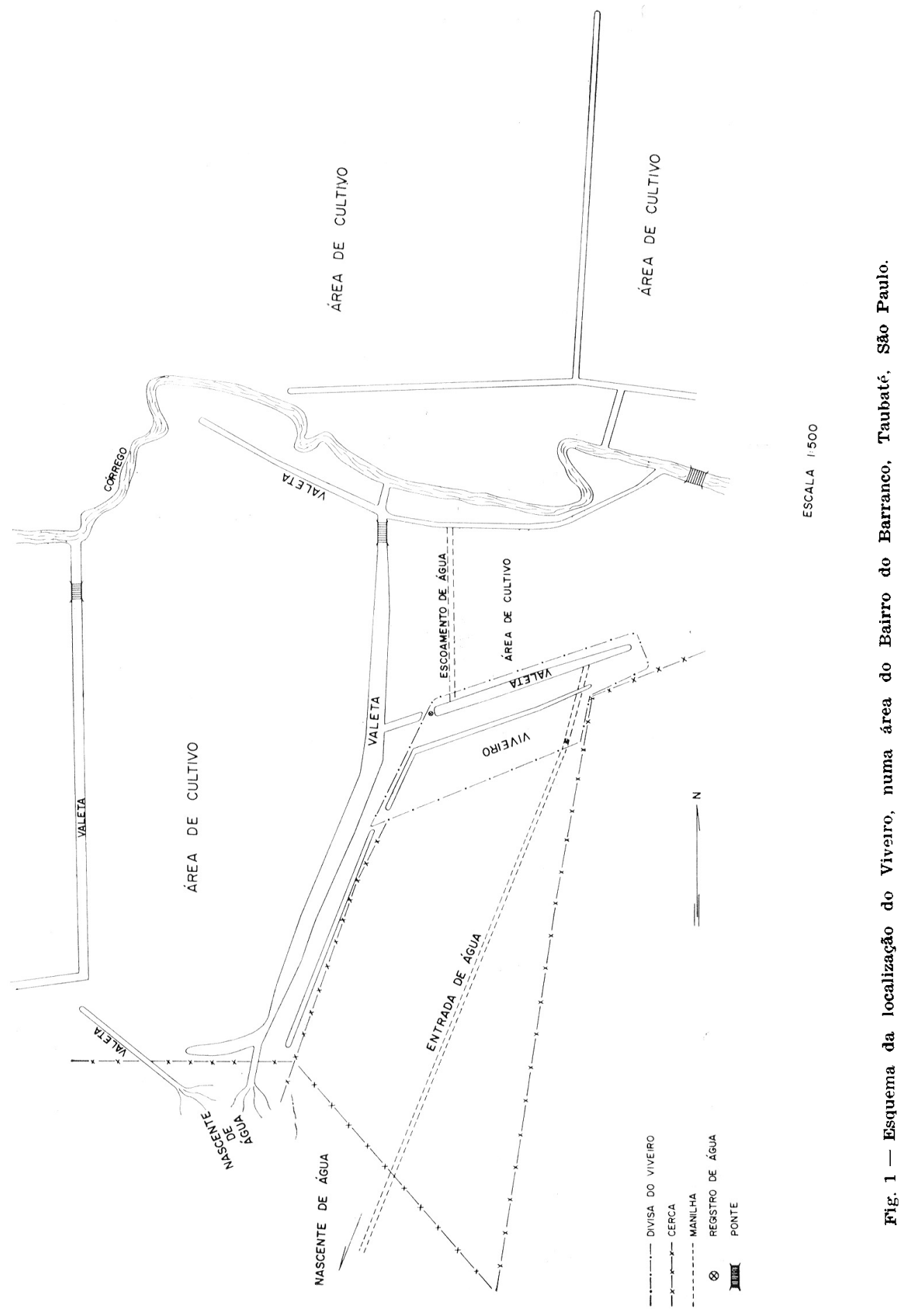


KAWAZOE, U. \& PINTO, A.C.M. Importância epidemiológica de alguns animais silvestres na esquistossomose mansônica. Rev. Sauide puibl., S. Paulo, 17:345-66, 1983.

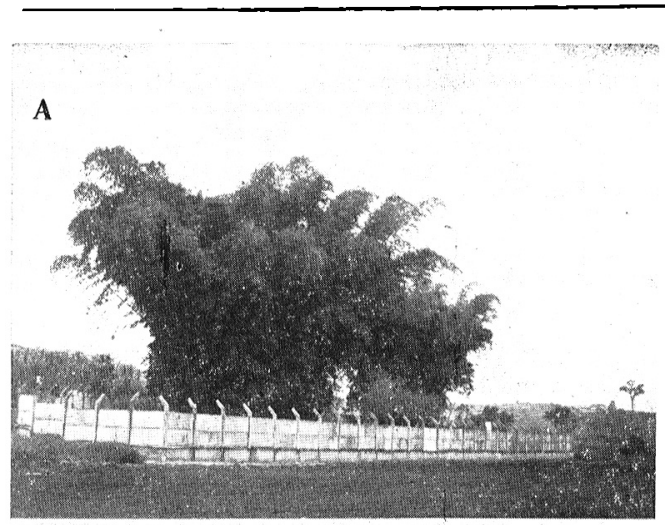

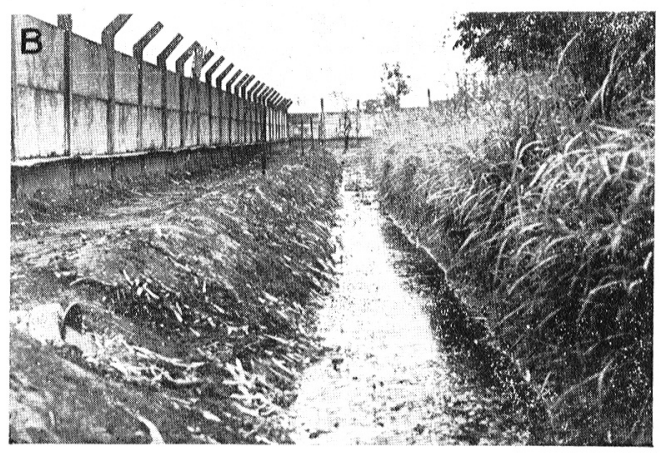

Fig. 2 - A: Vista panorâmica do Viveiro; B: Vista parcial do Viveiro, destacando-st a vala. Bairro do Barranco, Taubaté, São Paulo.

Durante o experimento, foram colocados, em duas ocasiões, camundongos-sentinela, durante $30 \mathrm{~min}$, em dois pontos distintos da vala, a fim de detectar a possível presença de cercárias de $S$. mansoni.

\section{Procedimento no Laboratório}

Os animais capturados eram levados para o laboratório (em Taubaté), onde eram registrados os seguintes dados: data e hora da capturá, número da armadilha, tipo de isca, localidade, medida do corpo, cauda, orelha interna, pé e peso corporal, sexo, gravidez, pesquisa de ovos de $S$. mansoni, número de campo e de registro. Os animais cram nimıerados com marcaçũo nas orelhas e mãos. Em cada captura, era verificado o numero uo alumäl, nos exenpiares recapturados, ou eram teitas maicaçoes $t m$ allinials captusauos pela primeira vez.

Para pesquisa de ovos de $S$. mansoni tor uttizado o melodu ae Kato quantitativo (curauo por honuya a hovayasm 20), com conteç̧au de tres lammas para cada amostra de fezes. $U$ exame microscópico for realtzado no laboratorio da Universiacaue de Campınas.

Os animais encontracios mortos no Viveiro ou que haviam morrido na armadilha eram levados parä o laboratorio once eram efetuadas as medidas de praxe. Procedra-se, entao, a necrópsia e pesquisa cic esquistossomos adultos nas veias mesentéricas, porta e intra-hepáticas através de esmagamento do figado. Além disso, eram realizadas pesquisas de elementos esquistossomóticos pela leitura dos oogramas 40 intestino delgado, grosso e reto, segundo técnica de Prata ${ }^{33}$ (1957) e Pellegrino e col.31 (1962). Us animais taxicuernizados e os crânios conservados eram utilizados para sua classificaçāo.

Os planorbídeos capturados eram levados ao laboratório, expostos à luz artificial durante duas horas, para pesquisa de cercárias de $S$. mansoni. Após o exame, todos os planorbideos eram novamente devolvidos à vala originai.

\section{RESULTADOS}

Durante o periodo do experimento forarr computados 41 exemplares de $H$. b. leucogaster, 45 de $O$. n. eliurus, 4 de $Z$. lasiurus e 6 de C. a. aperea (Tabela 1). Deste total foram introduzidos no Viveiro, 8 exemplares de $H$. b. leacogaster previamente infectados e 19 não infectados pelo $S$. mansoni, tendo nascido no local 14 exemplares. As outras espécies de roedores introduzidas não estavam infectadas e nem se tornaram positivas ao $S$. mansoni durante o experimento. Dos exempalres de Oryzomys, 10 foram introduzidos e 35 nasceram no local. 
KAWAZOE, U. \& PINTO, A.C.M. Importância epidemiológica de alguns animais silvestres nu esquistossomose mansônica. Rev. Saúde públ., S. Paulo, 17:345-66, 1983.

T A B E L A 1

Espécie e número de roedores presentes no Viveiro (bairro do Barranco, Taubaté), SP, durante o período de agosto de 1973 a dezembro de 1976.

\begin{tabular}{|c|c|c|c|c|c|}
\hline \multirow{2}{*}{$\begin{array}{c}\text { Espécie de } \\
\text { roedores }\end{array}$} & \multicolumn{2}{|c|}{ Introduzidos } & \multicolumn{2}{|c|}{ Nascidos } & \multirow{2}{*}{ Total } \\
\hline & $\mathbf{M}$ & $\mathbf{F}$ & $\mathrm{M}$ & $F$ & \\
\hline H. b. leucogaster & 14 & 13 & 6 & 8 & 41 \\
\hline o. $n$. eliurus & 4 & 6 & 16 & 19 & 45 \\
\hline Z. lasiurus & 2 & 2 & - & - & 4 \\
\hline C. a. aperea & 2 & 4 & - & - & 6 \\
\hline
\end{tabular}

$\mathrm{M}=$ macho: $\mathrm{F}=$ fềmea.

As espécies $Z$. lasiurus e $C$. a. aperea não procriaram no cercado.

Com o objetivo de acompanhar cada exemplar de $H$. b. leucogaster no Viveiro foram confeccionados dois diagramas com os seguintes dados: número do animal, data em que foi introduzido ou capturado pela primeira vez, número de vezes em que foi recapturado, tempo de permanência, presença ou não de ovos de 3 . mansoni nas fezes e finalmente, data de óbito, quando foi possivel a determinação.

O diagrama da Fig. 3 apresenta dados referentes ao período de agosto de 1973 a outubro de 1974: o exemplar no 848 , naturalmente infectado quando colocado no Viveiro, permaneceu vivo durante 340 dias, tendo sido possivel assinalar as ocasiōes em que foram encontrados ovos de $S$. mansoni em suas fezes. O exemplar no 850, infectado experimentalmente, foi capturado apenas duas vezes e não mais foi encontrado. Os de números 860,865 e 867 , nascidos no Viveiro, não apresentaram infecção natural; foram infectados em laboratório, cada um com 100 cercárias e recolocados no local; o diagrama da Fig. 3 assinala as épocas em que neles foram encontrados ovos do trematódeo. Em agosto de 1973, mais $9 H . b$. leucogaster, sabidamente não infectados, foram introduzidos no Viveiro para servir de elemento de observação, quanto à infec- ção natural e à sua procriação. Em setembro de 1974 , foi colocado mais um exemplar infectado com 80 cercárias cuja permanência no cercado foi acompanhada durante um curto período. Além desses animais, ainda foi possivel verificar a presença de mais 9 Holochilus nascidos no Viveiro $\mathrm{e}$ identificados após as capturas períodicas realizadas. Entre novembro de 1974 e abril de 1975 , nāo foram capturados roedores, nas tentativas de captura habitualmente realizadas.

O diagrama da Fig. 4 retrata a situação dos holochilus no periodo de maio de 1975 a dezembro de 1976. Dos 20 exemplares assinalados no diagrama, 5 haviam sido introduzidos depois de infectados no laboratório e outros 10 sem apresentarem infecção esquistossomótica; houve, portanto, o aparecimento de mais 5 exemplares nascidos no cercado.

Pelo exame dos dois diagramas, verifica-se que foi possível assinalar o óbito de apenas 6 exemplares, pelo encontro dos respectivos cadáveres. Outros roedores desapareceram sem deixar vestígios.

Durante todo o periodo de observação, somente no ano de 1976 é que se verificou infecção natural de $H$. b. leucogaster por $S$. mansoni, nos animais 923 e 932, como se observa no diagrama da Fig. 4. Pelo fato 
KAWAZOE, U. \& PINTO, A.C.M. Importancia epidemiológica de alguns animais silvestres ná esquistossomose mansônica. Rev. Saúde públ., S. Paulo, 17:345-66, 1983.

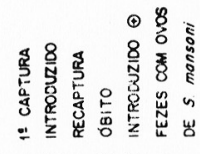

政

$\times$ 冈0 00

ถั

울

ว

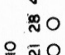

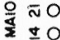

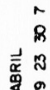

$\stackrel{8}{B}$

$\frac{8}{2}$

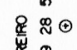

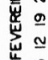

角

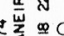

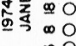

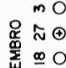

离

里 กิ

总 $\mathrm{m}$

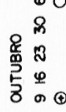

要

蛋

n० O 0

응

p蓶

$\delta$

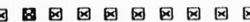

\section{!}

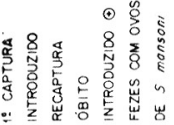

$\times$ 冈
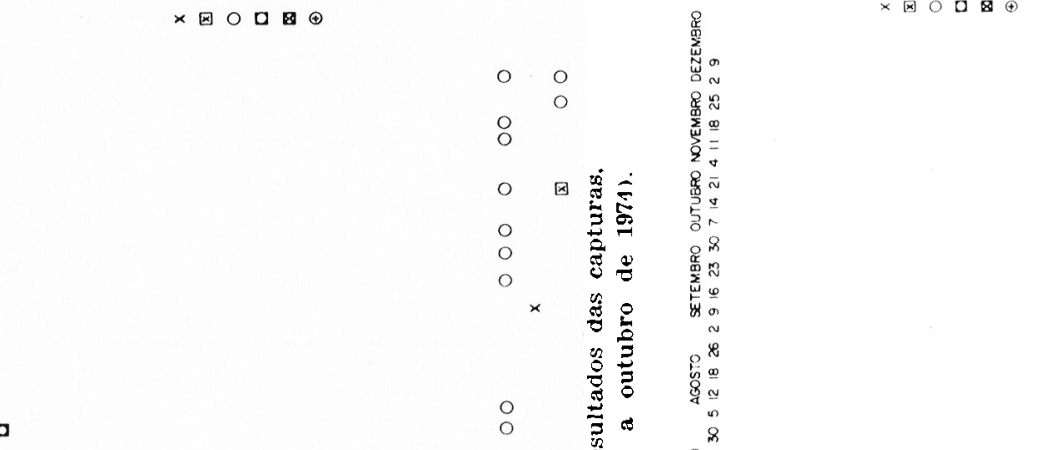

कृ

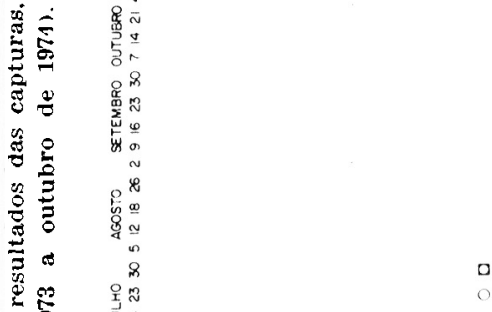

$\vec{a}$

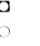

용

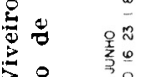

00

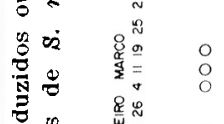

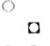

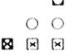

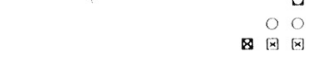

胥

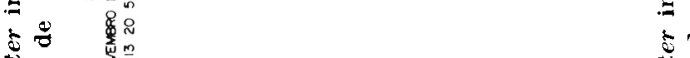

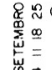

$\sum_{\infty}^{\infty}$

$\underbrace{\infty}_{\infty}$
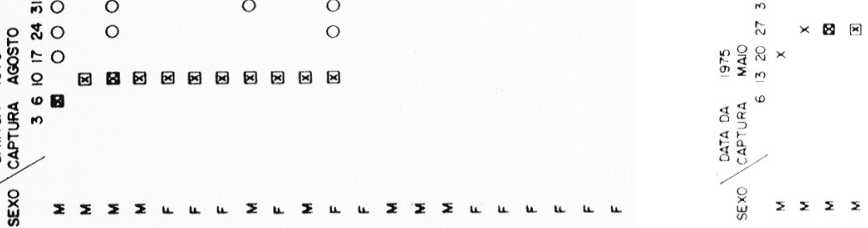

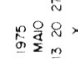

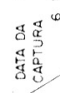

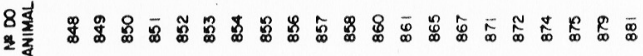


KAWAZOE, U. \& PINTO, A.C.M. Importância epidemiológica de alguns animais silvestres na esquistossomose mansônica. Rev. Saúde públ., S. Paulo, $17: 345-66,^{\prime} 1983$.

de os ovos terem sido encontrados entre setembro-dezembro, parece que a infecção deva ter ocorrido entre agosto-setembro.

De todos os $H$. b. leucogaster previamente infectados e introduzidos no Viveiro, apenas 2 foram encontrados no local após o óbito. O de n' 848, com infecção natural, foi introduzido no dia 6 de agosto de 1973 e a história deste roedor encontra-se na Tabela 2 ; nota-se que, em algumas ocasiões, houve eliminação de ovos nas fezes, apenas em pequena quantidade. Este animal foi encontrado maltratado e morto, fora da armadilha, provavelmente vitima de pessoa estranha. A pesquisa de elementos esquistossomóticos no reto deste animal encontra-se na Tabela 3 .

O Holochilus n० 911, infectado no laboratório com cerca de 100 cercárias (linhagem
SJ), foi introduzido no Viveiro no dia 11 de março de 1976. Durante sua permanência, foram encontrados ovos nas fezes duas vezes: no dia 25-05-76, eliminando 333,3 oros/grama de fezes e no dia 27-05-76 com 3.697,0 ovos/grama de fezes. O roedor foi encontrado morto na armadilha (30-07-76), quando foi necropsiado, verifjcando-se a presença de vermes adultos (40 machos e 20 fêmeas) na veia intrahepática, e um casal na veia porta, ou seja, $62,0 \%$ de cercárias que atingiram o estádio adulto. A observação microscópica da mucosa intestinal mostrou, desde a parte anterior do intestino (região do piloro), número enorme de ovos (principalmente mortos e cascas), - mesmo sendo verificado por toda parte restante do intestino. O oograma dos elementos esquistossomóticos dos segmentos do intestino está representado na Tabela 4 .

T A B E L A 2

Ficha individual de Holochilus b. leucogaster n' 848 .

$\begin{array}{cl}\text { Roedor }- \text { No de campo: } & \text { Espécie: } H . b . \text { leucogaster } \\ 848 & \text { Sexo: macho }\end{array}$

\begin{tabular}{|c|c|c|c|c|c|}
\hline $\begin{array}{l}\text { Data da } \\
\text { captura }\end{array}$ & $\begin{array}{c}\text { Peso } \\
\text { (g) }\end{array}$ & $\begin{array}{l}\text { Compr. } \\
\text { do corpo } \\
(\mathrm{mm})\end{array}$ & $\begin{array}{l}\text { Compr. } \\
\text { da cauda } \\
(\mathrm{mm})\end{array}$ & $\begin{array}{c}\text { Pé } \\
(\mathrm{mm})\end{array}$ & $\begin{array}{l}\text { Ovos/g } \\
\text { de fezes }\end{array}$ \\
\hline $06-08-73$ & - & - & - & - & 0 \\
\hline $17-08-73$ & 147,8 & - & - & - & 0 \\
\hline $24-08-73$ & 145,2 & - & - & 一 & 0 \\
\hline $31-08-73$ & 147,8 & - & - & - & 0 \\
\hline $14-09-73$ & 151,4 & - & - & - & 0 \\
\hline $28 \cdot 09-73$ & 161,2 & - & - & - & 0 \\
\hline $09-10-73$ & 175.0 & - & - & - & 81.1 \\
\hline $06-11-73$ & - & 198 & 46 & 174 & 0 \\
\hline $20-11-73$ & 172,4 & 182 & 43 & 175 & 0 \\
\hline $27-11-73$ & 102,0 & 156 & 43 & 170 & 0 \\
\hline $11-12-73$ & 183.0 & 190 & 45 & 183 & 0 \\
\hline $18-12-73$ & 183.1 & 165 & 44 & 165 & 0 \\
\hline $27-12-73$ & 165.8 & 185 & 45 & 176 & 205,1 \\
\hline $03-01-74$ & $: \cup 8.1$ & 170 & 42 & 175 & 0 \\
\hline $08-01-74$ & 183,0 & 174 & 45 & 176 & 0 \\
\hline $18-01-74$ & 193,1 & 170 & 49 & 170 & 0 \\
\hline $28-02-74$ & 192,4 & 183 & 44 & 169 & 66.7 \\
\hline $20-03-74$ & 206.2 & 205 & 45 & 175 & 0 \\
\hline $02-04-74$ & 189,5 & 208 & 11 & 178 & 90,9 \\
\hline
\end{tabular}

Obs.: o anımal fol solto no Viveiro previamente infectado pelo $S$. mansoni. 
KAWAZOE, U. \& PINTO, A.C.M. Importancia epidemiológica de alguns animais silvestres na esquistossomose mansônica. Rev. Saúde públ., S. Paulo, 17:345-66, 1983.

T A $\quad$ B $\quad$ E $\quad$ L A $A$

Holochilus b. leucogaster no 848 , naturalmente infectado com S. mansoni: elementos esquistossomóticos verificados no reto.

\begin{tabular}{lrr}
\hline \multirow{2}{*}{$\begin{array}{c}\text { Elementos } \\
\text { Esquistossomóticos }\end{array}$} & \multicolumn{2}{c}{ Número de ovos } \\
\cline { 2 - 3 } & Total & \multicolumn{1}{c}{} \\
\hline 10 estádio & 20 & 6,7 \\
2o estádio & 4 & 1,4 \\
3o estádio & 3 & 1,0 \\
4o estádio & 170 & 57,2 \\
Maduro & 43 & 14,5 \\
Morto & 45 & 15,2 \\
Casca & 12 & 4,0 \\
Total & 297 & 100,0 \\
\hline
\end{tabular}

A tabela mostra maior número de ovos mortos e cascas em toda extensão do intestino e número relativamente menor de elementos esquistossomóticos nos primeiros estádios de desenvolvimento.

A Tabela 5 apresenta o resumo dos dados encontrados nos diagramas das Figs. 3 e 4 , onde estão registrados o número e o período de permanência (em dias) dos Holochilus introduzidos e nascidos no
Viveiro bem como o número de roedores introduzidos ou nascidos no local, porém nāo recapturados. Do total de 27 animais introduzidos, 15 não foram recapturados, tendo possivelmente morrido. Dos recapturados uma ou mais vezes, o animal com 346 dias de observação foi o de mais longa permanência no Viveiro. Dentre os nascidos no Viveiro, o que apresentou maior tempo de sobrevida, durou 224 dias, em 1974.

Ainda em relação aos diagramas das Figs. 3 e 4, juntamente com a Tabela 6 , estão assinalados a data da primeira captura dos roedores nascidos ou introduzidos, pelo corporal nessa ocasiāo, peso máximo atingido por animal e período de permanência dos mesmos no cercado. A partir destes dados, foi possível calcular a provável época de nascimento de alguns roedores: os exemplares 860,861 e 865 , na segunda quinzena de setembro de 1973; os animais 871 e 872 , provavelmente na segunda quinzena de novembro; 874 e 875 , no início de março de 1974 e o no 879 , entre julho a agosto de 1974. Os animais 883 e 882 , entre março-abril de 1975; os roedores 923 e 924 , na primeira quinzena de maio e o de $n^{\circ} 932$, em julho de 1976.

T A B E L A 4

Holochilus b. leucogaster no 911 experimentalmente infectado com S. mansoni: elementos esquistossomóticos verificados no trato intestinal.

\begin{tabular}{|c|c|c|c|c|c|c|c|c|}
\hline \multirow{3}{*}{$\begin{array}{l}\text { Elementos } \\
\text { esquistosso- } \\
\text { móticos }\end{array}$} & \multicolumn{8}{|c|}{ Regiōes do intestino } \\
\hline & \multicolumn{2}{|c|}{ fleo } & \multicolumn{2}{|c|}{ Delgado } & \multicolumn{2}{|c|}{ Mesentério } & \multicolumn{2}{|c|}{ Reto } \\
\hline & Total & $\%$ & Total & $\%$ & Total & $\%$ & Total & $\%$ \\
\hline 10 estádio & 25 & 6,2 & 20 & 5,0 & 113 & 11,0 & 58 & 7,7 \\
\hline 2o estádio & 0 & - & 6 & 1,5 & $\mathbf{5}$ & 0,4 & 5 & 0.7 \\
\hline 3o estádio & 14 & 3,5 & 18 & 4,5 & 12 & 1,0 & 20 & 2,7 \\
\hline $4^{\circ}$ estádio & 67 & 16,8 & 68 & 17,0 & 14 & 1.2 & 80 & 10,7 \\
\hline Maduro & 16 & 4,0 & 20 & 5,0 & 192 & 15,8 & 61 & 8,1 \\
\hline Morto & 164 & 41,0 & 110 & 27,5 & 38 & 3,1 & 285 & 38,0 \\
\hline Casca & 114 & 28,5 & 158 & 39,5 & 521 & 43,0 & 241 & 32,1 \\
\hline Total & 400 & 100,0 & 400 & 100,0 & 1.212 & 100,0 & 750 & 100,0 \\
\hline
\end{tabular}


KAWAZOE, U. \& PINTO, A.C.M. Importancia epldemiológica de alguns animais silvestres nu esquistossomose mansônica. Rev. Saúde públ., S. Paulo, 17:345-66, 1983.

Acompanhando-se o desenvolvimento do roedor no 923 (Tabela 7 ) desde a sua primeira captura, com $15 \mathrm{~g}$ de peso corporal e provavelmente com 7 dias de vida, verificou-se que após 76 dias (05-08-76), atingiu $160 \mathrm{~g}$ de peso corporal e nessa época deu cria a 4 filhotes. Portanto, o roedor levou cerca de 60 dias para tornar-se sexualmente adulto podendo-se admitir que este rocdor tenha se acasalado, aproximadamente, no dia 16 de julho de 1976 , calculado o tempo de gravidez em cerca de 20 dias

Com a finalidade de moctrar o desenvolvimento dos Holochilus que permaneceram por tempo mais longo no Viveiro, foram confeccionadas as Figuras 5 e 6 com dados de peso corporal em função do tempo, tendo sido realizado o "alisamento" dos dados originais (Mosteller e Turkey ${ }^{27}, 1977$ c Dacher ${ }^{17}, 1978$ ). Observa-se que, à medida que o roedor cresce, seu peso aumenta e este aumento é bastante homogêneo, quando se comparam diferentes exemplares.

A Tabela 8 informa sobre a situação de planorbídeos encontrados na vala do Viveirc, durante o período de outubro de 1973 a dezembro de 1976: até final de 1975 não apareceu nenhum exemplar eliminando cercárias, e o número de caramujos $(B$. tenagophila) por captura foi bastante redu-

T A B E L A 5

Holochilus b. leucogaster, nascidos ou introduzidos no Viveiro: número total de exemplares observados, tempo de permanência de cada animal e número de exemplares recapturados ou năo (bairro do Barranco, Taubaté, SP) no período de agosto de 1973 a dezembro de 1976.

\begin{tabular}{|c|c|c|c|c|c|c|c|c|c|c|}
\hline \multirow{3}{*}{$\begin{array}{l}\text { Animais } \\
\text { Sexo }\end{array}$} & \multicolumn{4}{|c|}{ Introduzidos } & \multicolumn{5}{|c|}{ Nascidos } & \multirow{3}{*}{ Total } \\
\hline & \multicolumn{2}{|c|}{$\begin{array}{c}\text { Recapt. } \\
\text { (no de dias) }\end{array}$} & \multicolumn{2}{|c|}{$\begin{array}{l}\text { Não recapt. } \\
\text { (no de an.) }\end{array}$} & \multicolumn{3}{|c|}{$\begin{array}{c}\text { Recapt. } \\
\text { (no de dias) }\end{array}$} & \multicolumn{2}{|c|}{$\begin{array}{l}\text { Não recapt. } \\
\text { (no de an.) }\end{array}$} & \\
\hline & $\mathbf{M}$ & $F$ & $\mathbf{M}$ & $\mathbf{F}$ & & $\mathbf{M}$ & $\mathbf{F}$ & $\mathbf{M}$ & $F$ & \\
\hline \multicolumn{11}{|l|}{1973} \\
\hline & 340 & - & - & - & 78 & 156 & 一 & - & & \\
\hline Permanência & 22 & 110 & 3 & 4 & 135 & 24 & 1 & - & & \\
\hline (dias) & 75 & - & 一 & - & - & 99 & - & - & & \\
\hline Sub-total & 3 & 1 & 3 & 4 & 2 & 3 & 1 & - & & 17 \\
\hline \multicolumn{11}{|l|}{1974} \\
\hline Permanência & 一 & 42 & - & 一 & - & 8 & - & 1 & & \\
\hline (dias) & - & - & - & - & - & 224 & - & - & & \\
\hline Sub-total & 0 & 1 & 0 & 0 & 0 & 2 & 0 & 1 & & 4 \\
\hline \multicolumn{11}{|l|}{1975} \\
\hline & 346 & - & - & - & - & - & - & - & & \\
\hline Permanência & 143 & 73 & 4 & 3 & 136 & - & 1 & - & & \\
\hline (dias) & 10 & 一 & - & - & - & - & - & 一 & & \\
\hline Sub-total & 3 & 1 & 4 & 3 & 1 & 0 & 1 & 0 & & 13 \\
\hline \multicolumn{11}{|l|}{1976} \\
\hline Permanência & 142 & 44 & - & 1 & 一 & 140 & 1 & - & & \\
\hline (dias) & - & 15 & 一 & 一 & - & 120 & 一 & 一 & & \\
\hline Sub-total & 1 & 2 & 0 & 1 & 0 & 2 & 1 & 0 & & 7 \\
\hline
\end{tabular}

$\mathrm{M}=$ macho; $\mathrm{F}=$ fêmea. 
KAWAZOE, U. \& PINTO, A.C.M. Importancia epldemiológica de alguns animais silvestres n* esquistossomose mansonica. Rev. Saúde públ., S. Paulo, 17:345-66, 1983.

\section{T A B E L A 6}

Holochilus $b$, lencogaster, nascidos ou introduzidos no Viveiro, com pelo menos uma recaptura, (bairro do Barranco, Taubaté, SP) no período de agosto de 1973 a dezembro de 1976.

\begin{tabular}{|c|c|c|c|c|}
\hline $\begin{array}{l}\text { Número do } \\
\text { animal }\end{array}$ & $\begin{array}{l}\text { 19 captura } \\
\text { (data) }\end{array}$ & $\begin{array}{c}\text { Peso } \\
\text { inicial }(g)\end{array}$ & $\begin{array}{c}\text { Período de } \\
\text { permanência } \\
\text { (número de dias) }\end{array}$ & $\begin{array}{c}\text { Peso } \\
\text { máximo (g) }\end{array}$ \\
\hline \multicolumn{5}{|c|}{ Introduzidos no Viveiro } \\
\hline 848 & $06-08-73$ & 147,8 & 340 & 198.2 \\
\hline 849 & $10-08-73$ & 22,4 & - & - \\
\hline 850 & $10-08-73$ & 237,2 & 22 & $216, \delta$ \\
\hline 851 & $10-08-73$ & 29,1 & - & - \\
\hline 855 & $10-08-73$ & 229,9 & 75 & 256,0 \\
\hline 858 & $10-08-73$ & 129,6 & 110 & 176,0 \\
\hline 885 & $27-05-75$ & 166,5 & 346 & 250,0 \\
\hline 893 & $19-08-75$ & 120,0 & 75 & 190,0 \\
\hline 911 & $11-03-76$ & 100,0 & 142 & 100,0 \\
\hline 913 & $11-03-76$ & 125,0 & 44 & 180,0 \\
\hline \multicolumn{5}{|c|}{ Nascidos no Viveiro } \\
\hline 860 & $09-10-73$ & 38,8 & 156 & 173,0 \\
\hline 861 & $09-10-73$ & 25,0 & - & - \\
\hline 865 & $23-10-73$ & 74,4 & 78 & 149,0 \\
\hline 867 & $30-10-73$ & 112,5 & 101 & 130.0 \\
\hline 871 & $18-12-73$ & 28,5 & 9 & 35,4 \\
\hline 872 & $18-12-73$ & 33,8 & 99 & 110,0 \\
\hline 874 & $13-03-74$ & 20,0 & 7 & 22,0 \\
\hline 875 & $13-03-74$ & 48,4 & 224 & 139,2 \\
\hline 879 & $13-08-74$ & 130,3 & - & - \\
\hline 882 & $27-05-75$ & 21,0 & - & - \\
\hline 883 & $20-05-75$ & 185,0 & 36 & $\overline{210}, 0$ \\
\hline 923 & $21-05-76$ & 15,0 & 140 & 200,0 \\
\hline 924 & $27-05-76$ & 20,0 & - & - \\
\hline 932 & $05-08-76$ & 120,0 & 120 & 150,0 \\
\hline
\end{tabular}

T A B E L A 7

Ficha individual de Holochilus $b$. leucogaster $n^{\circ} 923$ Roedor: no de campo: 923 Espécie: $H$. b. leucogaster Sexo: fêmea

\begin{tabular}{lccccc}
\hline $\begin{array}{l}\text { Data da } \\
\text { captura }\end{array}$ & $\begin{array}{c}\text { Peso } \\
(\mathrm{g})\end{array}$ & $\begin{array}{c}\text { Compr. } \\
\text { do corpo } \\
(\mathrm{mm})\end{array}$ & $\begin{array}{c}\text { Compr, } \\
\text { da cauda } \\
(\mathrm{mm})\end{array}$ & $\begin{array}{c}\text { Pé } \\
(\mathrm{mm})\end{array}$ & $\begin{array}{c}\text { Ovos/g } \\
\text { de fezes }\end{array}$ \\
\hline $21-05-76$ & 15 & 115 & 110 & 35 & 0 \\
$27-05-76$ & 80 & 160 & 143 & 40 & 0 \\
$15-06-76$ & 100 & 160 & 145 & 40 & 0 \\
$01-07-76$ & 100 & 155 & 150 & 40 & 0 \\
$30-07-76$ & 150 & 180 & 150 & 40 & 0 \\
$05-08-76^{*}$ & 160 & 172 & 150 & 40 & 0 \\
$18-08-76$ & 150 & 182 & 152 & 43 & 0 \\
$09-09-76$ & 150 & 185 & 155 & 45 & 140,3 \\
$16-09-76$ & 150 & 185 & 155 & 45 & 117,6 \\
$23-09-76$ & 150 & 190 & 157 & 45 & 29,0 \\
$07-10-76$ & 200 & 150 & 155 & 45 & 0 \\
\hline
\end{tabular}

Obs.: o animal nasceu no Viveiro e adquiriu $S$. mansoni no local.

* o animal deu cria a 4 filhotes, no biotério. 
KAWAZOE, U. \& PINTO, A.C.M. Importancia epidemiológica de alguns animais stTvestres na esquistossomose mansônica. Rev. Saude públ., S. Paulo, 17:345-66, 1983.

\section{TA B L A 8}

Frequéncia de planorbídeos introduzidos ou capturados na vala do Viveiro e indice de infeç̧ăo ao S. mansoni (bairro do Barranco, Taubaté, SP) no perfodo de outubro de 1973 a a dezembro de 1976 .

\begin{tabular}{|c|c|c|c|c|c|c|c|c|c|}
\hline \multirow{2}{*}{ Data } & \multicolumn{4}{|c|}{ No de exemplares } & \multirow{2}{*}{ Total } & \multicolumn{3}{|c|}{+ para S. mansoni } & \multirow{2}{*}{$\begin{array}{l}\text { Espécie de } \\
\text { planorbideos }\end{array}$} \\
\hline & Vivos & Mortos & con & ncha & & & No & $\%$ & \\
\hline \multicolumn{10}{|l|}{1973} \\
\hline $09-10$ & 1 & - & & 2 & 3 & & - & - & B. tenagophila \\
\hline $22-10$ & - & - & & 一 & - & & - & - & B. tenagophila \\
\hline $20-11$ & 1 & - & & - & 1 & & - & - & B. tenagophila \\
\hline $27-11$ & \multicolumn{9}{|c|}{ Limpeza da vala } \\
\hline 04-12 & 1 & - & & - & 1 & & - & - & B. tenagophila \\
\hline $27-12$ & 1 & - & & - & 1 & & - & - & B. tenagophila \\
\hline \multicolumn{10}{|l|}{1974} \\
\hline $28-01$ & $114^{*}$ & (adultos) & & - & 114 & & - & -- & B. tenagophila \\
\hline $13-03$ & 10 & 10 & & - & 20 & & - & -- & B. tenagophila \\
\hline $26-03$ & 6 & 7 & & - & 13 & & - & -- & $B$, tenagophila \\
\hline $17-04$ & $167^{*}$ & (adultos) & & - & 167 & & - & - & B. tenagophila \\
\hline $14-05$ & 2 & 1 & & - & 3 & & - & - & B. tenagophila \\
\hline $28-05$ & - & - & & - & - & & - & - & \\
\hline 23-06 & Limpeza & da vala. & Intr & roduz & desove & as de c & caramujos & (foco & Taubaté). \\
\hline $18-07$ & \multicolumn{9}{|c|}{ Introduzidas desovas procedentes de Caçapava (foco 25). } \\
\hline \multicolumn{10}{|l|}{1975} \\
\hline $06-01$ & 20 & 6 & & $\rightarrow$ & 26 & & - & - & B. tenagophila \\
\hline $21-01$ & 3 & 4 & & 一 & 7 & & -- & - & B. tenagophila \\
\hline $04-02$ & 3 & - & & - & 3 & & - & - & B. tenagophila \\
\hline $10-06$ & 33 & 3 & & 一 & 36 & & - & - & B. tenagophila \\
\hline $24-06$ & 10 & 2 & & - & 12 & & - & - & B. tenagophila \\
\hline $08-07$ & 3 & 1 & & - & 4 & & - & - & B. tenagophila \\
\hline $19-08$ & \multicolumn{3}{|c|}{ Introdt:zidas desovas } & \multicolumn{5}{|c|}{ procedentes da Unicamp. } & \\
\hline $05-09$ & 8 & - & & - & 8 & & - & - & B. glabrata \\
\hline $18-09$ & 17 & - & & - & 17 & & - & - & B. glabrata \\
\hline $30-10$ & 13 & - & & - & 13 & & - & - & B. glabrata \\
\hline \multicolumn{10}{|l|}{1976} \\
\hline $12-02$ & 110 & - & & - & 110 & & - & -- & B. glabrata \\
\hline $26-02$ & 400 & - & & - & 100 & & 8 & 2,0 & B. glabrata \\
\hline $11-03$ & 250 & - & & - & 250 & & 4 & 1,6 & B. glabrata \\
\hline $08-04$ & 112 & - & & - & 112 & & - & - & B. glabrata \\
\hline $13-05$ & 125 & - & & - & 125 & & 1 & 0,8 & B. glabrata \\
\hline $25-05$ & 146 & - & & - & $140^{\circ}$ & & - & - & B. glabrata \\
\hline $10-06$ & 164 & - & & - & 164 & & - & - & B. glabrata \\
\hline $01-07$ & 105 & - & & - & 105 & & - & - & B. glabrata \\
\hline $06-08$ & 120 & - & & - & 120 & & - & - & B. glabrata \\
\hline 26-08 & 82 & - & & - & $\delta 2$ & & - & -- & B. glabrata \\
\hline $30-09$ & 42 & - & & - & 42 & & - & - & B. glabrata \\
\hline $08-10$ & 33 & - & & - & 33 & & - & - & B. glabrata \\
\hline $04-11$ & 93 & - & & - & 93 & & -- & - & B. glabrata \\
\hline $18-11$ & 51 & - & & - & 51 & & - & - & B. glabrata \\
\hline $02-12$ & 57 & - & & - & 57 & & - & - & B. glabrata \\
\hline $16-12$ & 68 & - & & - & 68 & & - & - & B. glabrata \\
\hline
\end{tabular}

* Introduzidos no Viveiro. 
KAWAZOE, U. \& PINTO, A.C.M. Importancia epidemiológica de alguns animais silvestres na esquistossomose mansónica. Rev. Saúde públ., S. Paulo, 17:345-66, 1983.

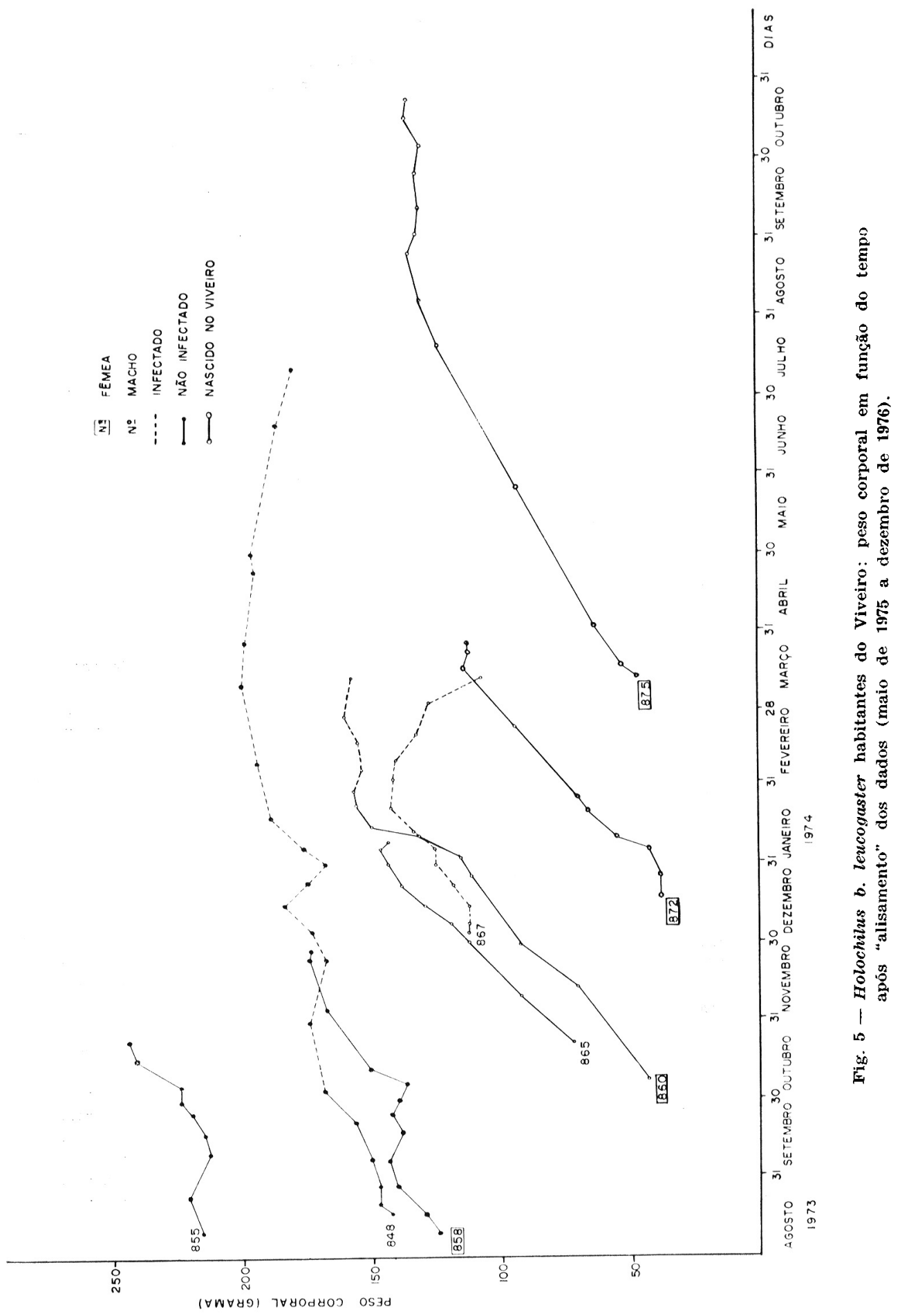

358 
KAWAZOE, U. \& PINTO, A.C.M. Importancia epidemiológica de alguns animais silvestres na esquistossomose mansônica. Rev. Saúde públ., S. Paulo, 17:345-66, 1983 .
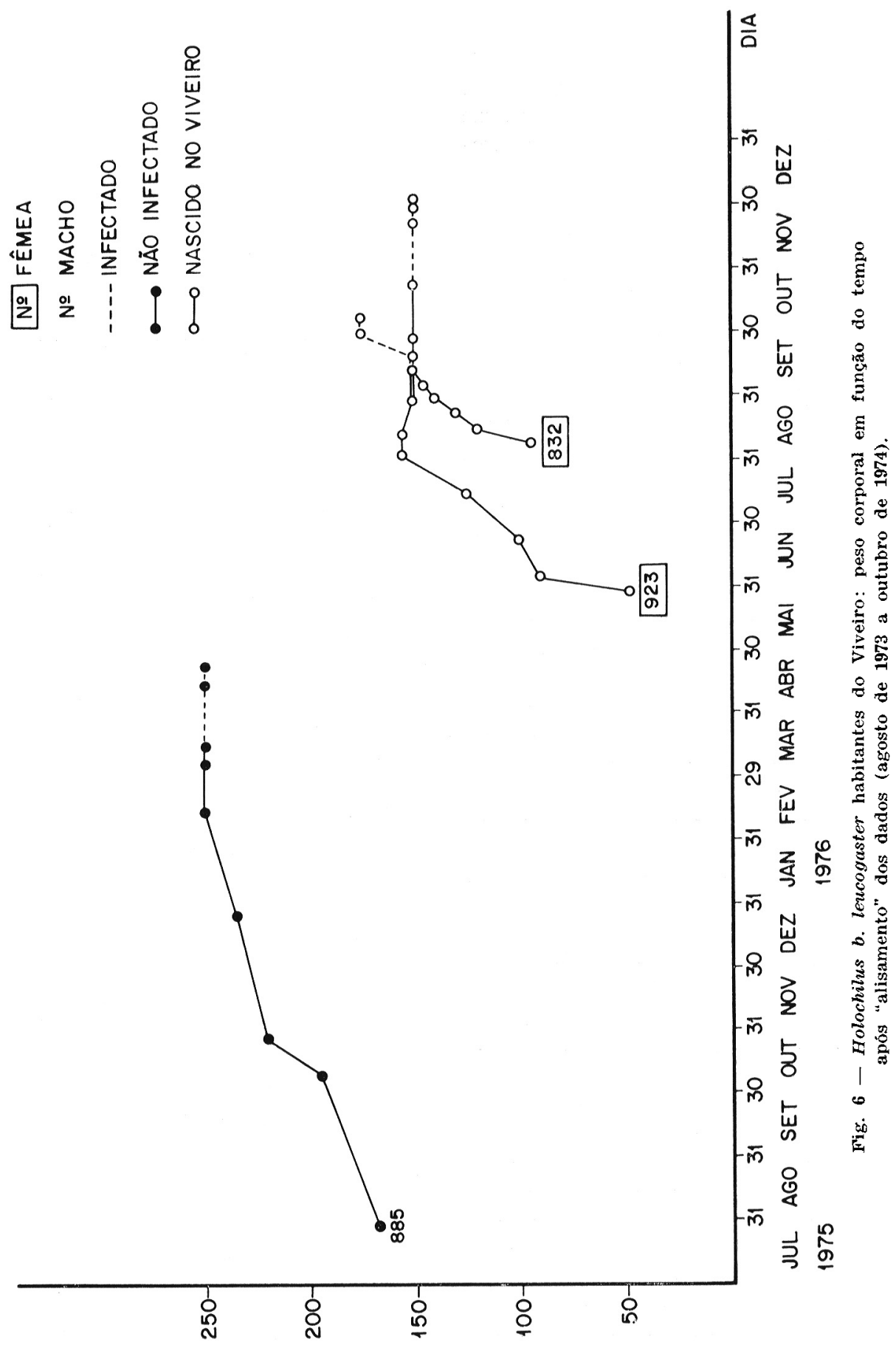

( $\forall W \forall Y 9) 7 \forall Y O d Y O J$ OS $\exists d$ 
KAWAZOE, U. \& PINTO, A.C.M. Importancia epidemiológica de alguns animais silvestres na esquistossomose mansónica. Rev. Saúde públ., S. Paulo, 17:345-66, 1983.

zido; a partir de 1976, foram coletados pla. norbídeos naturalmente infectados e eliminando cercárias em três ocasiões, embora com baixo indice de infecção. É provável que isto tenha ocorrido em conseqüência da introdução acidental, na vala, de desovas de $B$. glabrata, espécie mais prolífica (Kawazoe ${ }^{21}$, 1977) e mais suscetivel ao $S$. mansoni (Paraense e Corrêa 29,30, 1963; Magalhães 24, 1969 e Guaraldo 20, 1976). Nesta Tabela estão também registradas a data em que os planorbídeos foram introduzidos na vala, sua procedência e a época em que foram realizadas limpezas.

A comprovação da presença de cercácias na água suspeita da vala foi realizada colocando-se camundongos-sentinela no local: foram utilizados 6 camundongos albinos (16-03-76) em dois pontos distintos. Dois destes animais foram necropsiados (22-07-76), estando negativos para $S$. mansoni. Não foi possível realizar a necrópsia dos outros camundongos, pois haviam morrido em final de semana e os orgãos estava'n putrefatos. No dia 18-11-76, foram banhados mais 10 camundongos, durante $30 \mathrm{~min}$, em dois pontos distintos da vala. Sete desses camundongos morreram no dia 14-02-77 e não foi possível fazer sua necróspsia. Outros três animais foram necropsiados e um deles apresentou-se infectado com o parasita.

\section{DISCUSSAO E CONCLUSOEES}

O experimento demonstrou que a manutenção do ciclo de $S$. mansoni entre agosto de 1973 a janeiro de 1976 não foi bem sucedida quando foram utilizados planorbídeos $B$. tenagophila como hospedeiro intermediário. Durante o tempo de obser. vação houve a ocorrência de fatores imprevistos, prejudiciais ao andamento do trabalho, como a presença de predadores naturais de roedores (gavióes e corujas) e as condições climáticas, com chuvas abundantes em determinados periodos, influindo negativamente na proliferaçăo de planorbideos bem como dos roedores.
Somente em 1976 quando, inadvertidamente, foram introduzidas desovas de $B$. glabrata é que se conseguiu realmente completar o ciclo de $S$. mansoni. Nessa ocasião, foram obtidas infecçōes de alguns exemplares de caramujos (Tabela 8), com eliminação de cercárias que infectaram alguns roedores participantes da experiência. $H$. b. leucogaster foi a única espécie a mostrar positividade ao parasitismo através do encontro de ovos nas fezes. Apenas dois deles, nascidos no Viveiro, adquiriram a infecção, tendo sobrevivido 140 e 120 dias, respectivamente, com eliminação de 29 a 140 ovos por grama de fezes, nas ocasiões em que foi possivel detectar a infecção. Deve-se ressaltar que o tempo de permanência desses dois roedores na área foi relativamente curto (cerca de 4 meses), o que possivelmente não seria suficiente para a manutenção contínua do ciclo.

Entretanto, Holochilus mostrou-se bastante suscetivel ao $S$. mansoni, eliminando ovos viáveis nas fezes, e os animais necropsiados apresentaram grande quantidade de vermes adultos; os oogramas demonstraram ovos em diversos estádios de desenvolvimento, como mostram as Tabelas 3 e 4 .

Portanto, quando foi utilizada $B$. tenagophila, espécie presente nos focos e criadouros do Vale do Rio Paraiba do Sul, não foi possivel a manutenção do ciclo do parasita. Esta observação vem mostrar que é extremamente difícil ao roedor manter o ciclo da esquistossomose, na ausência da contaminação humana. Provavelmente, a manutenção do ciclo extra-humano tenha sido facilitada pela presença de um hospedeiro intermediário mais suscetivel, como é o caso de $B$. glabrata, o que aliás ocorreu neste trabalho. $\mathrm{O}$ fato já havia sido assinalado por Antunes ${ }^{5}$ (1971) e Antunes e col. ${ }^{6}$ (1973), em ambiente "semi-natural", onde B. glabrata funcionou como hospedeiro intermediário e Nectomys s. squamipes como hospedeiro definitivo. Fato semelhante foi também observado por Carvalho ${ }^{13}$ (1974) e Carvalho e col.14 (1975), quando utilizaram 
KAWAZOE, U. \& PINTO, A.C.M. Importancia epidemiologica de alguns animais silvestres na esquistossomose mansônica. Rev. Saúde públ., S. Paulo, 17:345-66, 1983.

B. glabrata como hospedeiro intermediário e $H$. brasiliensis como hospedeiro definitivo. Após esses resultados, os referidos autores aventaram a hipótese de que determinados roedores silvestres possam funcionar como reservatório da esquistossomose, cada caso devendo ser considerado de maneira distinta, em cada local, na dependência de ecossistemas favoráveis.

É provável que isso ocorra em determinadas áreas onde exista, em abundância, o hospedeiro vertebrado suscetível, como é o caso de $H$. brasiliensis ou de Nectomys $s$. squamipes, que estão freqüentemente em contato com a água, juntamente com o hospedeiro intermediário de boa suscetibilidade, como é o caso de B. glabrata. Entretanto, e este fato não foi observado na natureza até a presente data, no continente americano, onde os roedores ou outros mamiferos naturalmente parasitados foram capturados em regiões de área endêmica da esquistossomose humana e é provável que estivessem parasitados com a linhagem humana de $S$. mansoni. Favorecendo esta hipótese pode-se citar o trabalho de Amorim 2 (1962) que verificou o decréscimo do indice de roedores parasitados, quando capturados à maior distância das habitações (mais de $400 \mathrm{~m}$ ). Martins ${ }^{26}$ (1958) também havia mencionado que a prevalência de $S$. mansoni em roedores estaria ligada à prevalência da esquistossomose humana. Este fato foi igualmente verificado por Dias 18 (1976) que encontrou, na mesma zona por nós estudada, $30,2 \%$ de Holochilus com infecção natural por $S$. mansoni. $\mathrm{Na}$ ocasião, $22 \%$ da população humana local apresentou positividade para ovos desse helminto.

Antunes ${ }^{5}$ (1971) comenta que os roedores estariam transformando, segundo a classificação de Nelson ${ }^{29}$ (1960), uma associação típica zooantroponose numa anfixenose, em zonas de média e alta endemicidade. Seriam, pois, roedores de hábitos semi-aquáticos os reservatórios do parasita que poderiam manter um ciclo do $S$. mansoni paralelo ao mantido pelo homem colaborando para a manutenção da esquistossomose humana. Barbosa ${ }^{\top}$ (1972), também parece confirmar as observaçóes dos outros autores, quando verificou, em Pontezinha (PE), que os roedores parecem não contribuir para a manutenção do ciclo do Schistosoma, tendo sido considerados hospedeiros de importância secundária.

Rey 3 (1973) julga que não se pode excluir a possibilidade de que os roedores "sejam antes vitimas de uma antroponose, por viverem perto dos homens, do que reservatórios animais efetivos, capazes de manter o ciclo parasitário independentemente". Por outro lado, Dias ${ }^{18}$ (1976) é de opinião que a importância dos roedores estaria relacionada com a sua densidade populacional.

Pelos nossos estudos na região do Vale do Rio Paraiba do Sul, é provável que, nessa região, Holochilus b. leucogaster dificilmente manterá o ciclo do parasita, na ausência da poluição humana, se $B$. tenagophila for o hospedeiro intermediário. Este caramujo é menos suscetível e contrai a infecção com menor frequiência que $B$. glabrata.

Com relação a observações de campo de Holochilus é interessante ressaltar as que foram realizadas por Dias 18 (1976), em Taubaté, onde assinalou variação da densidade de $H$. b. leucogaster, por hectare, entre zero a 41,$5 ; 27,7$ e 20,7 , respectivamente, utilizando o índice de Lincoln-Petersen, métodos de Bailey e Fleming, tendo sido mais abundante nos meses secos do que nos chuvosos. Este fato mostra que o animal é relativamente escasso na regiăo. O tempo de permanência no local da captura variou entre 46 dias na época seca e 70 dias durante as chuvas, tendo percorrido a distância ao longo das valas da linha de captura, de 8 a $273 \mathrm{~m}$, o que significa uma distância relativamente curta que não permitiria grande disseminação de ovos. Outro fato, também verificado pelo autor acima citado ${ }^{18}$, refere-se à sobrevivência de $H . b$. leucogaster capturados naturalmente infectados e mantidos em cativeiro após a cap- 
KAWAZOE, U. PINTO, A.C.M. Importancia epidemiológica de alguns animais silvestres na esquistossomose mansônica. Rev. Saúde públ., S. Paulo, 17:345-66, 1983.

tura: 9 dos 21 animais tiveram sobrevida de mais de 200 dias; no entanto, 5 deles apresentaram sobrevida superior a $\mathbf{5 0 0}$ dias.

As atuais observações permitiram colher dados referentes a $41 \mathrm{H} . \quad$ b. leucogaster, habitando o Viveiro. Dentre os animais introduzidos, 15 não mais foram recapturados e entre os nascidos no local, 4 desapareceram. Por outro lado, do total de animais, 11 não sobreviveram mais que 100 dias e apenas 10 atingiram mais de 100 dias, 7 deles tendo nascidos no local. O animal que sobreviveu por mais tempo completou 346 dias, com 9 recapturas. Os roedores, não recapturados após a primeira captura, provavelmente devem ter tido morte natural, ou talvez tenham sido vitimas de predadores, como corujas e gaviōes, frequientemente vistos no local. Portanto, apenas a quarta parte do total de roedores sobreviveram por tempo mais longo, o que representa um número relativamente pequeno, para que pudessem atuar como reservatórios da esquistossomose.

Dos animais nascidos no Viveiro, os mais jovens capturados pela primeira vez estavam com cerca de $15 \mathrm{~g}$ e 7 dias de vida, o que significa que estariam expostos a um risco de infecção, desde as primeiras semanas de vida. Entretanto, em sua maioria, os animais capturados pela primeira vez pesavam, em média, 20 a $50 \mathrm{~g}$, havendo outros pesando pelo menos $100 \mathrm{~g}$ e considerados adultos.

A avaliação do crescimento de $H . \quad b$. leucogaster foi realizada utilizando-se como parâmetro o peso corporal (Figs. 5 e 6). Apesar da pequena amostra, pode-se notar que o peso aumentou com o tempo e parece não estacionar até a morte do animal. É provável que a infecção não tenha influência sobre o peso do animal. Esses dados não săo de inteira fidelidade, devido ao tipo de balança rudimentar utilizada no laboratório de campo; entretanto, estão concordes com as observaçōes de Dias 18 (1976), em seu trabalho de campo, apesar das informaçōes disponiveis serem escassas e não permitirem uma conclusão definitiva.

Os resultados encontrados no Viveiro parecem indicar que, em ambiente favorável, com espaço suficiente para a sobrevivência dos roedores e alimentação em abundância, não há época marcada para a sua reprodução. Na natureza, entre fatores limitantes, existem os de competição e espaço vital. Entretanto, não foi grande o número de animais procriados no Viveiro, durante - periodo de observação. Dias 18 (1976) verificou, na natureza, que o acasalamento dos roedores deu-se em períodos determinados, de fevereiro a maio (final da estação chuvosa) e o outro entre setembro a outubro (final da estação seca).

Nas demais espécies de roedores que habitaram o Viveiro, não foram encontrados exemplares parasitados com S. mansoni, ao longo do experimento. No entanto, na região de Taubaté, já foram assinalados casos positivos dessa helmintose na ratureza, com baixo indice de infecção (Dias ${ }^{18}$, 1976 e Dias e col.19, 1978). Nossas observaçōes estão de acordo com as dos autores acima mencionados que, na mesma região, examinando 13 exemplares de $Z$. lasiurus, encontraram apenas um parasitado com $S$. mansoni e de $140 . n$. eliurus capturados no campo verificaram estar todos negativos.

Essas duas espécies não apresentam hábitos semi-aquáticos, freqüentando esporadicamente as coleções d'água. Em nossas observações, Oryzomys n. eliurus, de hábitos parcialmente arborícolas e por não ocupar o mesmo nicho do Holochilus, procriou no Viveiro permanecendo, em média, menos de 100 dias. Zygodontomys lasiurus foi introduzido no cercado, porém não houve procriação, o mesmo verificando-se com Cavia a. aperea, que apesar de freqüentar os banhados, não apresentou infecção pelo $S$. mansoni. A partir de 1975, esta espécie não mais foiint roduzida no Viveiro. Devido ao baixo índice de infecção natural 
KAWAZOE, U. \& PINTO, A.C.M. Importância cpidem.ológıca de algums an.ma:s silvestres na esquistossomose mansônica. Rer. Saúde públ., S. Paulo, 17:345-66, 1983.

desses roedores, admite-se que os mesmos não devam apresentar importância primordial na epidemiologia da esquistossomose.

Com relação à presença de planorbídeos na vala do Viveiro, nota-se pelo exame da Tabela 9 que, até agosto de 1975, a população de caramujos foi bastante reduzida, presumindo-se que o criadouro não oferecia condições adequadas para a vivência de $B$. tenagophila, introduzidos no local. Ressalte-se ainda que, segundo Coelho ${ }^{15.16}, 1975$ e 1962 e Guaraldo 20 1979, esses moluscos oferecem certa resistência no que diz respeito ao desenvolvimento da fase larvária do S. mansoni. Este fato parece ter ocorrido no decurso do presente trabalho, dada a ausência de caramujos positivos à infecção. Entretanto, a partir de feverereiro de 1976 , quando já estavam presentes numerosos exemplares de B. glabrata, verificou-se, nestes últimos, a eliminação de cercárias em três ocasiōes. Como consequiência, $2 \mathrm{H}$. b. leucogaster, nascidos no Viveiro, adquiriram a infecção, o mesmo ocorrendo com alguns camundongos albinos-sentinela, em contato com a água.

Este fato vem confirmar, mais uma vez, a maior suscetibilidade e proliferação de $B$. glabrata e, possivelmente, a grande eleminaçāo de cercárias nos exemplares infectados que possibilitaria maior contato desta com o hospedeiro vertebrado, especialmente os de hábitos semi-aquáticos, como nos casos de Holochilus ou Nectomys. Isso sugere que, em áreas onde há presença deste hospedeiro intermediário, há maior chance deste se infectar e completar o ciclo em hospedeiro vertebrado não humano, desde que esteja presente em alta densidade.

A Tabela 8 mostra que o pico da freqüência de $B$. glabrata foi entre fevereiro-março de 1976, período em que alguns dos exemplares estavam eliminando cercárias e provavelmente época favorável para que houvesse infecção de alguns mamiferos. Dias ${ }^{18}$ (1976), também verificou maior freqüência de $B$. tenagophila em fevereiro- -márço, porém a infecção desses planorbideos foi observada em julho e aezembro ue 1972; abril e maio de 19/3, com indices percentuais de 3,$8 ; 20,0 ; 16,7$ e 5,5 respectivamente, em $6(1,5 \%)$ dos 397 exemplares, o que representa taxa bastante pequena, em relaçáo ao número de exemplares examınados.

Deste modo, Holochilus brasiliensis ieucugaster, especie relatwamente freqüence na região do Vale do Rio Paraiba do Sul (SP), demonstrou ser suscetivel ao Schistosoma mansoni, elıminando grande número de ovos viáveis do trematódeo, pelo menos durante um curto período da infecção. Parece, entretanto, que seu papel é irrelevante na cadeia epidemiológica da esquistossomose, nessa região, conforme observações feitas neste trabalho, pois, a cadeia $H . b$. leucogaster $\rightarrow B$. tenagophila $\rightarrow H$. b. leucogaster não foi veriticada. Deste modo, os roedores de hábitos semi-aquáticos nāo estariam agindo como hospedeiro reservatório e sim como uma associação zooantroponose em relação ao S. mansoni, e o homem seria o único hospedeiro definitivo importante da cadeia epidemiológica da esquistossomose mansônica, na reglão estudada.

Provavelmente, nesse local, o encontro de roedores com infecção natural seja devido a presença de linhagem humana e estes animais seriam hospedeiros acidentais adquirindo a parasitose quando em contato com coleções d'água contaminadas.

Com a eventualidade do aparecimento $e$ desenvolvimento de uma linhagem do $S$. mansoni, de melhor adaptação à $B$. tenagophila, é possivel que o papel representado por $H . b$. leucogaster passe a ter maior significação no ciclo biológico do trematódeo.

Não obstante, cabe ressaltar, que em outras regiões de esquistossomose humana, no Brasil, onde o hospedeiro intermediário é $B$. glabrata, é possivel que o roedor venha a desempenhar sério papel como disseminador de ovos, quando encontrado em alta densidade. Como demonstração deste fato. 
KAWAZOE, U. \& PINTO, A.C.M. Importância epidemiológica de alguns animais silvestres na esquistossomose mansônica. Rev. Saúde públ., S. Paulo, 17:345-66, 1983.

no presente trabalho, foi possivel completar 0 ciclo do $S$. mansoni em $H$. b. leucogaster e $B$. glabrata, na ausência do homem parasitado, com relativa facilidade. Este fato, talvez venha reforçar a hipótese de que tais hospedeiros vertebrados estejam se transformando, de uma associação tipicamente zooantroponótica, em uma anfixenose, como vem afirmando certos autnres.

\section{AGRADECIMENTOS}

Ao Prof. Dr. Luiz Cândido de Souza Dias pelo apoio na elaboração inicial deste trabalho.

Ao funcionário Carlos Táu, da SUCEN, Taubaté, pela execução da parte técnica deste trabalho, no local em que o experimento foi realizado.

KAWAZOE, U. \& PINTO, A. C. M. [Epidemiologic importance of some wild rodents

in the schistosomiasis mansoni]. Rev. Saúde públ., S. Paulo, 17:345-66, 1983.

ABSTRACT: The importance of some wild rodents as possible reservoir hosts of S. mansoni related to the epidemiologic chain of this parasite and some biological aspects of these rodents were studied in semi-natural habitats. The experiment was performed in an enclosed area of about $1,000 \mathrm{~m}^{2}$ situated in Taubaté, State of S. Paulo, one of the endemic area of human schistosomiasis, during a period of three years and six months (from August 1973 to December 1976). Wild rodents of the following species were used as definitive hosts: Holochilus brasiliensis leucogaster, Zygodontomys lasiurus, Oryzomys nigripes eliurus and Cavia aperea aperea. Biomphalaria tenagophila and B. glabrata were used as intermediate hosts. From August 1973 to January 1976 it was not possible to find any B. tenagophila eliminating S. mansoni cercariae nor any rodents infected with the same parasite. In August, 1975, egg patches of B. glabrata snails were accidentaly introduced into the area and in 1976 some adult snails were eliminating $\mathbf{S}$. mansoni cercariae. In that same year, two Holochilus that were born in the area were discharging S. mansoni eggs in their feces. Some biological data were collected from $41 \mathrm{H}$. b. leucogaster of which 28 individuals were introduced into and 14 were born in the area. The majority of body weights of rodents born in the area and captured for the first time was between 20 and 50 grams. In this group of 41 rodents observed, body weight continued to increase throughout the life span of each individual sampled. $\mathbf{Z}$. lasiurus and $\mathbf{C}$. a. aperea did not show any infection with $\mathbf{S}$. mansoni and they did not leave any progeny in the area. $\mathbf{O}$. n. eliurus reproduced in the area and remaining there for about 100 days did not show any infection with the parasite. Thus, $\mathbf{H}$. b. leucogaster and $\mathbf{B}$. tenagophila, in the absence of infected humans, will harcily maintain the life cicle of schistosomiasis but Holochilus together with B. glabrata would probably maintain the life cicle of $\mathbf{S}$. mansoni in nature without the presence of infected man, since in the area there is a suitable strain of $\mathbf{S}$. mansoni, both for definitive and intermediate hosts.

UNITERMS: Schistosomiasis. Schistosoma mansoni. Biomphalaria glabrata. Biomphalaria tenagophila. Holochilus brasiliensis leucogaster. Reservoir. 
KAWAZOE, U. \& PINTO, A.C.M. Importancia epidemiológica de alguns animais silvestres na esquistossomose mansônica. Rev. Saúde puibl., S. Paulo, 17:345-66, 1983.

\section{REFERENCIAS BIBLIOGRAFICAS}

1. AMORIM, J.P. Infecção experimental e natural de murídeos pelo Schistosoma mansoni [nota prévia]. Rev. bras. Malar. $5: 219-22,1953$.

2. AMORIM, J.P. Infeç̧ão do homem e de roedores silvestres pelo Schistosoma mansoni em localidades do municipio de Viçosa (Estado de Alagoas, Brasil). Arq. Hig. Saúde públ., 27:335-9, 1962.

3. AMORIM, J.P. Roedores selvagens como disseminadores de ovos de Schistosoma mansoni. Rev. Inst. Med. trop. S. Paulo, $4: 397-402,1962$.

4. AMORIM, J.P.; ROSA, D.A. \& LUCENA, D.T. Ratos silvestres, reservatórios do Schistosoma mansoni no nordeste do Brasil. Rev. bras. Malar, 6:13-28, 1954.

5. ANTUNES, C.M.F. Nectomys squamipes squamipes Brants, 1827 na epidemiologia da esquistossomose mansoni. Belo Horizonte, 1971. [Dissertação de Mestrado - Instituto de Ciências Biológicas da UFMG].

6. ANTUNES, C.M.F.; MILWARD DE AN DRADE, R.; KATZ, N.; COELHO, P.M.Z. \& PELLEGRINO, J. Role of Nectomys squamipes squamipes in the epidemiology of Schistosoma mansoni infection. Ann. trop. Med. Parasit., $67: 67-73,1973$.

7. BARBOSA, F.S. Natliral infection with Schistosoma mansoni in small mammals trapped in the course of a schistosos miasis control project in Brazil. $J$. Parasit., 58:405-7, 1972.

8. BARBOSA, F.S.; DOBBIN JR., E.A. \& COELHO, M.V. Infeç̧ão natural de Rattus rattus frugivorus por Schistosoma mansoni em Pernambuco. Publ. Inst. Aggeu Magalhães, 2(4):43-46, 1953.

9. BARBOSA, F.S.; PINTO, R. \& SOUZA, O.A. Control of schistosomiasis mansoni in a small North East Brazilian Community. Trans. roy. Soc. trop. Med. Hyg., $65: 206-13,1971$.

10. BARRETTO, A.C. Infecção natural de ratos de esgoto (Rattus norvegicus) por Schistosoma mansoni, na cidade de Salvador, Bahia. Bol. Fund. Gonçalo Moniz, $14: 1-5,1959$
11. BARRETTO, A.C. Importância de animais como reservatório de esquistossomos humanos. Arq. Hig. Saúde públ., 29:95$-102,1964$.

12. BAStoS, O.C. Estudo do comportamento parasitológico e imunológico das linhagens humanas e silvestres do Schistosoma mansoni Sambon, 1907. São Paulo, 1975 [Dissertação de Mestrado - Insti. tuto de Biologia da UNICAMP].

13. CARVALHO, O.S. Roedores silvestres na epidemiologia da esquistossomose mansoni no Lago da Pampulha, Belo Horizonte, Minas Gerais (Brasil), com especial referência ao Holochilus brasiliensis (Rodentia, Cricetidae). Belo Horizonte, 1974. [Dissertação de Mestrado - Instituto de Ciências Biológicas da UFMG].

14. CARVALHO, O.S.; MILWARD DE ANDRADE, R. \& CORTES, M.I.N, Roedores silvestres na epidemiologia da esquistossomose mansônica no Lago da Pampulha, Belo Horizonte, Minas Gerais (Brasil). Rev. Soc. bras. Med. trop., 9:27-35, 1975 .

15. COELHO, M.V. Aspectos do desenvolvimento das formas larvais de Schistosoma mansoni em Australorbis nigricans. Rev. bras. Biol., 17:325-37, 1957.

16. COELHO, M.V. Suscetibilidade de Australorbis tenagophilus à infecção por Schistosoma mansoni. Rev. Inst. Med. trop. S. Paulo, 4:289-95, 1962.

17. DACHES, J.N.W. Análise de dados e regressão. Campinas, Departamento de Estatística, IMECC-UNICAMP, 1978. [Apostila].

18. DIAS, L.C.S. Aspectos parasitológicos e ecológicos da esquistossomose mansônica no Vale do Rio Paraíba do sul e na Represa de Americana, Estado de São Paulo, Brasil. São Paulo, 1976. [Tese de Doutoramento - Instituto de Biologia da UNICAMP].

19. DIAS, L.C.S.; AVILA-PIRES, F.S. \& PINTO, A.C.M. Parasitological and ecological aspects of schistosomiasis mansoni in the valley of Paraíba do Sul River (São Paulo State, Brazil). 1. Natural infection of small mammals with Schistosoma mansoni. Trans. roy. Soc. trop. Med. Hyg., 72:496-500. 1978. 
KAWAZOE, U. \& PINTO, A.C.M. Importância epidemiológica de alguns animaís slivestres na esquistossomose mansônica. $R=v$. Saúde públ., S. Paulo, 17:345-66, 1983.

20. GUARALDO, A.M.A. Desenvolvimento dos esporocistos de Schistosoma mansoni Sambon, 1907, em Biomphalaria glabrata (Say, 1818) e Biomphalaria tenagophila (d'Orbigny, 1835). São Paulo, 1979. [Dissertaçáo de Mestrado - Instituto de Bıologia da UNICAMF」.

21. KAWAZOE, U. Alg. ns aspectos da biologia de Biomphalaria glabrata (Say, 1018) e Biomphalaria tenagophila (d'Orbigny), 1835) (Plilmonata, Planorbidae). II Fecundidade e fertilidade. Rev. Saúde publ., S. Paulo, 11:47-64, 1977.

22. KAWAZOE, U.; DIAS, L.C.S. \& PIZA, J.T. Infecção natural de pequenos mamiferos por Schistosoma mansoni, na Represa de Americana (São Paulo, Brasil). Rev. Saúde públ., S. Paulo, 12:200-8, 1978.

23. KOMIYA, Y. \& KOBAYASHI, A. Evaluation of Kato's thick smear technic with cellophane cover for helminth eggs in feces. Jap. J. Med. Sci. Biol., 19:59-64, 1966.

24. MAGALhaES, L.A. Estudo dos dados obtidos de uma população de Biomphalaria glabrata de Belo Horizonte infectada por Schistosoma mansoni da mesma cidade, e de uma população de $B$. tenagophila de Campinas, infectada por $S$. mansoni de São José dos Campos. Rev. Soc. bras. Med. trop., 3:195-6, 1969.

25. MARTINS, A.V. Non human vertebrate host of Schistosoma haematobium and Schistosoma mansoni. Bull. Wld Hith Org., 18:931-44, 1958.

26. MARTINS, A.V.; MARTINS, G. \& BRITO, R.S. Reservatórios sllvestres do Schistosoma mansoni no Estado de Minas Gerais. Rev. bras. Malar, 7:259-65, 1955.
27. MOSTELLER, F. \& TURKEY, J.W. Data analysis and regression. Reading. Mass, Addison-Weesley Publ., 1977.

28. NELSON, G.S. Schistosome infections as zoonoses in Africa. Trans. roy. Sac. trop. Med. Hyg., 54:301-16, 1960 .

29. PARAENSE, W.L. \& CORREA, L.R. Varlation in suscetibility of population of Australorbis glabratus to a strain of Schistosoma mansoni. Rev. Inst. Med. trop. S. Paulo, 5:15-22, 1963.

30. PARAENSE, W.L. \& CORREA, L.R. SUscetibility of Australorbis tenagophilus to infection with Schistosoma mansoni. Rcv. Inst. Med. trop. S. Paulo, 5:23-ᄃ, 1963.

31. PELIEGRINO, J.; OLIVEIRA, C.A.; FARIA, J. \& CUNHA, A.S. New approach to the screening of drugs in chemoterapy of Schistosoma mansoni in mice. Amer. J. trop. Med. Hyg., 11:201-15, 1962.

32. PIVA, N. \& BARROS, P.R.C. Infecção natural de animais silvestres e domésticos pelo Schistosoma mansoni em Sergipe. Rev. bras. Malar., 18:221-33, 1966.

33. PRATA, A. Biópsia retal na esquistossomose mansoni e tratamento. Rio de Janeiro, Serv. Nacional Educ. Sanit., 1957. LTese de Doutoramento - Faculdade de Medicina da UFBa].

34. REY, J. Parasitologia. Rio de Janeiro, Ed. Guanabara Koogan, 1973.

Recebido para publicação em 28/02/1983

A provado para publicąão em 22/07/1983 